\title{
Clinical Experience of Using Active Transcutaneous Bone Conduction Implants (Bonebridge) in Children Under 5 Years Old
}

\author{
Seong Hoon Bae (i) - Youngrak Jung (i) - Jinsei Jung (i) - Jae Young Choi (i) \\ Department of Otorhinolaryngology, Yonsei University College of Medicine, Seoul, Korea
}

The Bonebridge active bone conduction implant (Med-El, Innsbruck, Austria) was developed to overcome the skin- and osteointegration-related complications of bone-anchored hearing aids (BAHAs). Hearing outcomes are comparable between patients with conductive hearing loss who receive the Bonebridge device and those who receive BAHAs [1]. The Bonebridge device is permitted for use in children over 5 years old in Europe and in those over 12 years old in the United States. The age limitations are based on concerns regarding the size and thickness of the skull, which are relatively insufficient for the floating mass transducer (FMT). The thickness of cortical bone in the retro-sigmoid area in a 3-year-old child is approximately $3.5 \mathrm{~mm} \mathrm{[2,3].} \mathrm{The} \mathrm{FMT}$ of the BCI 601 model (Med-El) is significantly thicker, at $8.7 \mathrm{~mm}$, and this discrepancy can theoretically result in intracranial complications. Nevertheless, hearing rehabilitation outcomes may be better when interventions are implemented early, as demonstrated in studies concerning cochlear implantation. Because early childhood is regarded as a critical period for language development [4], strategies to address these limitations may be necessary to improve patient outcomes.

In this report, we discuss six cases in which the Bonebridge implant was applied in Korean children under the age of 5 years. The feasibility of implantation in children younger than recommended ages is discussed in relation to our institutional experience. To the best of our knowledge, this is the first study to report Bonebridge outcomes and complications in children under

\footnotetext{
- Received December 8, 2021

Revised January 5, 2022

Accepted January 8, 2022

- Corresponding author: Jae Young Choi

Department of Otorhinolaryngology, Yonsei University College of Medicine and Severance Hospital, Yonsei University Health System, 50-1 Yonsei-ro, Seodaemun-gu, Seoul 03722, Korea

Tel: +82-2-2228-3484, Fax: +82-2-393-0580

E-mail: jychoi@yuhs.ac
}

the recommended age. We identified six children under the age of 5 years who received the Bonebridge implant between 2015 and 2020 (Table 1). Skull thickness was calculated from an axial computed tomography image of the temporal bone obtained at the level of the lateral semicircular canal. Skull thickness was defined as the average thickness of the thickest and thinnest parts of the retro-sigmoid area.

The Institutional Review Board of Severance Hospital approved this retrospective study (IRB No. 4-2021-1157). The requirement for informed consent was waived due to the retrospective nature of the study. Before surgery, parents were provided sufficient information, including the approved age range of the device. The decision to perform surgery was made after a thorough discussion and agreement with the parents. All operations were performed by one experienced ENT surgeon (JYC). The implanted model was the BCI 601 in all enrolled patients. The site of implantation was selected by the surgeon based on preoperative temporal computed tomography and direct surgical findings. Surgery was performed in accordance with the procedure recommended by the manufacturer. Auditory brainstem responses (ABRs) or pure-tone audiometry (PTA) were used to confirm conductive hearing loss. The test selected (ABR or PTA) was based on the patient's cooperation. If the patient was unable to understand conventional PTA, play PTA was conducted. Assessments of ABRs including bone conduction were performed if play PTA was also not possible.

The site of FMT implantation was determined mostly based on the status of the mastoid bone. For retro-sigmoid implantation, the skull was carefully drilled to create a thin island bony flap. After the dura was exposed, the skull and dura around the FMT well were gently dissected. Surgicel ${ }^{\circledR}$ was packed into the space between the dura and the skull. The sigmoid sinus was always identified and used as a landmark. No intraoperative complications, including cerebrospinal fluid leakage or bleeding, were

Copyright $\odot 2022$ by Korean Society of Otorhinolaryngology-Head and Neck Surgery

This is an open-access article distributed under the terms of the Creative Commons Attribution Non-Commercial License (https://creativecommons.org/licenses/by-nc/4.0) which permits unrestricted non-commercial use, distribution, and reproduction in any medium, provided the original work is properly cited. 
Table 1. Patient characteristics

\begin{tabular}{|c|c|c|c|c|c|c|c|c|c|}
\hline $\begin{array}{l}\text { Patient } \\
\text { No. }\end{array}$ & Sex & $\begin{array}{l}\text { Operative } \\
\text { age (mo) }\end{array}$ & $\begin{array}{c}\text { Skull } \\
\text { thickness } \\
(\mathrm{mm})\end{array}$ & $\begin{array}{l}\text { Follow-up } \\
\text { duration } \\
\text { (mo) }\end{array}$ & Side & $\begin{array}{c}\text { Contralateral } \\
\text { hearing } \\
\text { threshold }\end{array}$ & $\begin{array}{c}\text { Model/sound } \\
\text { processor }\end{array}$ & CHL etiology & Syndromic disease \\
\hline 1 & $\mathrm{~F}$ & 49 & 5.03 & 62 & L & No response & BCl 601/Amadé & $\begin{array}{l}\text { Ossicle anomaly }(\mathrm{L}) \\
\text { Microtia }(\mathrm{L})\end{array}$ & CHARGE syndrome \\
\hline 2 & M & 41 & 3.32 & 62 & $\mathrm{R}$ & No response & BCl 601/Amadé & $\begin{array}{l}\text { Ossicle anomaly }(B) \\
\text { EAC narrowing }(B)\end{array}$ & $\begin{array}{l}\text { Cornelia de Lange } \\
\text { syndrome }\end{array}$ \\
\hline 3 & M & 52 & 3.62 & 59 & $\mathrm{R}$ & $15 \mathrm{~dB}$ & BCl 601/Amadé & $\begin{array}{c}\text { Ossicle anomaly }(\mathrm{R}) \\
\text { Microtia }(\mathrm{R}) \\
\text { EAC atresia }(\mathrm{R})\end{array}$ & None \\
\hline 4 & M & 54 & 6.63 & 57 & L & $64 \mathrm{~dB}$ & BCl 601/Amadé & $\begin{array}{c}\text { Ossicle anomaly }(B) \\
\text { EAC narrowing }(R) \\
\text { EAC atresia }(L) \\
\text { Microtia }(L)\end{array}$ & None \\
\hline 5 & M & 43 & 3.96 & 54 & $\mathrm{R}$ & $70 \mathrm{~dB}$ & BCl 601/Amadé & $\begin{array}{l}\text { Ossicle anomaly (B) } \\
\text { EAC narrowing (B) }\end{array}$ & $\begin{array}{c}\text { Cornelia de Lange } \\
\text { syndrome }\end{array}$ \\
\hline 6 & M & 54 & 4.05 & 29 & L & $55 \mathrm{~dB}$ & BCl 601/Samba & $\begin{array}{l}\text { Ossicle anomaly (B) } \\
\text { EAC narrowing (B) }\end{array}$ & None \\
\hline
\end{tabular}

$\mathrm{CHL}$, conductive hearing loss; L, left; R, right; B, bilateral; EAC, external auditory canal.

observed. However, patient 3 exhibited lethargy immediately after discharge and developed paralysis of the left abducens nerve (CN6) 1 week after surgery. After a neurologic and ophthalmologic examination, the patient was diagnosed with increased intracranial pressure (IICP). After the Bonebridge device was removed, the patient recovered from the above-mentioned complications. No other patients experienced complications during the follow-up period.

Four of the six enrolled patients were examined using aided PTA.All patients experienced hearing gain using the Bonebridge device (Fig. 1). The mean of the average PTA threshold (average thresholds of $0.5,1,2$, and $4 \mathrm{kHz}$ frequencies) decreased from $58.8 \mathrm{~dB}$ (unaided air conduction threshold) to $28.3 \mathrm{~dB}$ (aided threshold). The smallest difference between the aided and bone conduction thresholds was observed at a frequency of $2 \mathrm{kHz}$.

We aimed to share our experience with Bonebridge implantation in children under 5 years old. Obvious hearing gains were observed following implantation in all patients. Furthermore, the surgical findings were unremarkable, and no long-term complications were identified. However, one of the six patients experienced serious complications associated with IICP shortly after surgery. Given that the FMT is thicker and larger relative to the skull in young children, IICP is a major concern. IICP has never been reported as a complication for adults and children after cochlear implantation, BAHA, or Bonebridge surgery [5-10]. In this regard, the IICP observed in this patient seems to have been associated with his young age.

Except for a risk of IICP, our findings indicate that the Bonebridge implant may be safe and beneficial for children under 5 years of age, as we observed no complications over a followup period of at least 2 years. In this study, the mean aided average PTA threshold was $28.3 \mathrm{~dB}$ (functional gain of $30.5 \mathrm{~dB}$ ), and

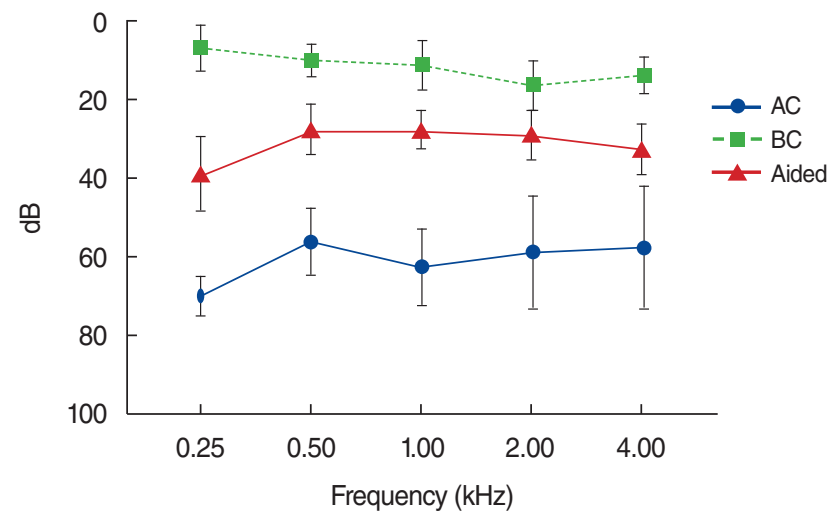

Fig. 1. The audiogram findings after the Bonebridge implant in younger children. Error bars indicate standard deviation. AC, air conduction; $\mathrm{BC}$, bone conduction.

the most effective frequency was $2 \mathrm{kHz}$. The functional gain was consistent with previously reported results for the Bonebridge implant [9]. The BCI 602 device has recently been commercialized and exhibits an FMT thickness of $4.5 \mathrm{~mm}$ from the surface of the skull, which is remarkably thinner than that of the BCI 601. This advance may significantly reduce the risk of complications resulting from compression of brain structures, including the dural venous sinus. Our findings highlight the need for future prospective studies to investigate the implantation of the BCI 602 device in younger children.

In conclusion, our findings indicate that the Bonebridge device can be implanted in children under 5 years old when extreme care is taken to avoid compression of the sigmoid sinus. Furthermore, functional gain was comparable to that observed in older patients, and no intraoperative or long-term complications were observed. 


\section{CONFLICT OF INTEREST}

No potential conflict of interest relevant to this article was reported.

\section{ACKNOWLEDGMENTS}

This research was supported by the Basic Science Research Program through the National Research Foundation of Korea (NRF) funded by the Ministry of Education (NRF-2020R1I1A1A01067241 to SHB).

\section{ORCID}

Seong Hoon Bae

Youngrak Jung

Jinsei Jung

https://orcid.org/0000-0001-9243-9392

https://orcid.org/0000-0001-7893-1866

https://orcid.org/0000-0003-1906-6969

Jae Young Choi

\section{AUTHOR CONTRIBUTIONS}

Conceptualization: JYC. Data curation: YJ, SHB. Formal analysis: SHB. Funding acquisition: JYC. Methodology: SHB, JYC. Project administration: YJ. Visualization: JJ, YJ. Writing-original draft: SHB.Writing-review \& editing: JJ, JYC.

\section{REFERENCES}

1. Li Z, Lai X, Lai J, Qi M,Yuan L, Zeng X, et al. Correction of the estimated hearing level of NB Chirp ABR in normal hearing population. Audiol Neurootol. 2022 Apr 20 [Epub]. https://doi.org/10.1159/ 000523918

2. Li Z, Park BK, Liu W, Zhang J, Reed MP, Rupp JD, et al. A statistical skull geometry model for children 0-3 years old. PLoS One. 2015 May;10(5):e0127322.

3. Ukatu CC, Desai NK, Todd NW Jr. Site for bone-anchored hearing system for children younger than 5 years. Otolaryngol Head Neck Surg. 2015 Feb;152(2):348-52.

4. Harrison RV, Gordon KA, Mount RJ. Is there a critical period for cochlear implantation in congenitally deaf children? Analyses of hearing and speech perception performance after implantation. Dev Psychobiol. 2005 Apr;46(3):252-61.

5. Farinetti A, Ben Gharbia D, Mancini J, Roman S, Nicollas R, Triglia JM. Cochlear implant complications in 403 patients: comparative study of adults and children and review of the literature. Eur Ann Otorhinolaryngol Head Neck Dis. 2014 Jun;131(3):177-82.

6. Kiringoda R, Lustig LR. A meta-analysis of the complications associated with osseointegrated hearing aids. Otol Neurotol. 2013 Jul; 34(5):790-4

7. Migirov L, Muchnik C, Kaplan-Neeman R, Kronenberg J. Surgical and medical complications in paediatric cochlear implantation: a review of 300 cases. Cochlear Implants Int. 2006 Dec;7(4):194-201.

8. Hobson JC, Roper AJ, Andrew R, Rothera MP, Hill P, Green KM. Complications of bone-anchored hearing aid implantation. J Laryngol Otol. $2010 \mathrm{Feb}$;124(2):132-6.

9. Sprinzl GM, Wolf-Magele A. The Bonebridge bone conduction hearing implant: indication criteria, surgery and a systematic review of the literature. Clin Otolaryngol. 2016Apr;41(2):131-43.

10. Crowder HR, Bestourous DE, Reilly BK. Adverse events associated with Bonebridge and Osia bone conduction implant devices. Am J Otolaryngol. 2021 Jul-Aug;42(4):102968. 